Atualidades de Pesquisa

\title{
FORMAÇÃO POR MEIO DOS IRDI COM PAIS E PROFESSORES: UMA PARCERIA POSSÍVEL NA EDUCAÇÃO INFANTIL
}

\section{Tese de Doutorado no Instituto de Psicologia da Universidade de São Paulo}

\author{
Autora \\ Cristina Keiko Inafuku de Merletti \\ Orientadora \\ Profa. Dra. Maria Cristina Machado Kupfer \\ (Universidade de São Paulo)
}

\section{Banca examinadora}

Profa. Dra. Leda Mariza Fischer Bernardino (Associação Psicanalítica de Curitiba), Profa. Dra. Andrea Gabriela Ferrari (Universidade Federal do Rio Grande do Sul), Profa. Dra. Rosa Maria Marini Mariotto (Pontifícia Universidade Católica do Paraná), Profa. Dra. Marie Claire Sekkel (Universidade de São Paulo) 
A relação família-escola, historicamente acompanhada de conflitos, torna-se objeto de preocupação crescente nas diretrizes políticas educacionais. A pesquisa verificou situações frequentes de rivalidade e de culpabilização decorrentes da relação ambivalente que pais e professores em creche, educadores primordiais dos bebês, estabelecem entre si na divisão das responsabilidades e das funções de cuidados destinadas a eles. Fundamentou-se uma metodologia de formação continuada para mediar esta relação família-escola por meio dos IRDI e dos princípios da Educação Terapêutica, ambos pautados na teoria psicanalítica. Verificou-se que os pais passaram a ressignificar suas funções educativas na relação com os filhos, considerando sua dimensão subjetiva. As professoras, por sua vez, apropriaram-se da formação realizada a partir de seu próprio saber e do desejo por seu ofício, encontrando meios de auxiliar singularmente os bebês no coletivo da instituição. A tese apresentou os fundamentos de um tratamento precoce das relações entre pais e professores na educação infantil por meio de uma metodologia de formação continuada, visando prevenir rupturas nesta relação inicial, colaborando para a articulação das funções educativas subjetivantes dos educadores e pais, e auxiliando a promoção da saúde mental no tempo da primeira infância. 